\title{
Energy Finance Data Warehouse: Tracking Revenues Through the Power Sector
}

\begin{abstract}
Reliable data is needed to understand financial relationships in the power sector. However, relevant data acquisition and visualization can be a challenge due to the fragmented nature of the power sector. A Sankey prototype can elucidate the 'big picture' of financial flows to understand the complex relationships between specific actors within the power sector and to address a major gap in financial policymaking.
\end{abstract}

Claire Zeng, Stephen Hendrickson, Sangkeun Matt Lee, Supriya Chinthavali, Jessica Lin, Eric Hsieh, Mallikarjun Shankar

Claire Zeng is an ORISE Fellow to the U.S. Department of Energy in the Energy Policy and Systems Analysis (EPSA-51) office. Her focus during her tenure has been on analysis and visualization of power sector data. She received her B.S. in Science, Technology and International Affairs from Georgetown University's School of Foreign Service.

Stephen Hendrickson is an analyst for Energy Finance and Incentives in the Office of Energy Policy and Systems Analysis at the U.S. Department of Energy. Since joining DOE in 2010, his work has included financial and policy analysis of the solar industry, natural gas and natural gas liquids, and advanced vehicle technologies, as well as energy tax policy and the project economics of power generation technologies. He served as an energy policy analyst at the White House Office of Science and Technology Policy in 2011-2012 and a graduate researcher at the National Renewable Energy Laboratory in 2009-2010. He has an M.B.A. from the University of Colorado, a Masters in International Development from the University of Pittsburgh, and a B.A. in Cultural Anthropology from the University of Michigan.

Sangkeun Matt Lee received the Ph.D. degree in Computer Science and Engineering from Seoul National University in 2012. He joined Oak Ridge National Laboratory as a post-doctoral research associate in 2013 and became a research staff member in 2015. His research interests include large-scale graph mining and analytics, big data systems and architectures, information retrieval and recommender systems, and their applications. He has experience of working on ORNL's Lab-directed Research \& Development (LDRD), US-DOE and NIH sponsored projects, and developing various software tools like gm-sparql (Graph Mining Using SPARQL) and ORiGAMI (Oak Ridge Graph Analytics for Medical Innovation).

Supriya Chinthavali has been working as a computer scientist in ORNL since March 2010. She has several years of experience working on US-DOE and DOD-sponsored projects like VERDE (Visualizing Energy Resources Dynamically on Earth), SPIDERS, PFMT, etc. in the Energy 
domain at ORNL. Prior to ORN, she worked for Delphi Automotive systems as an Advanced Software Engineer and developed embedded software systems for Toyota and GM. Her research interests include data analysis and information visualization of electric grid and complex infrastructure systems and machine learning. She graduated with a B.S. in Electronics and Communication and M.S. in Automotive Embedded Systems from Visvesvaraya Technological Institute in India (2008) and a M.S. in CSE from Georgia Institute of Technology (2015).

Jessica Lin is a Senior ORISE Fellow to the U.S. Department of Energy in the Finance Department of the Office of Energy Policy and System Analysis. Prior to her current role, she worked on international energy projects with the World Bank Group, primarily focusing on what role the Bank could play to commercialize clean energy technologies. She started her career in the private sector, working in finance and strategic management consulting, before leading a wireless mesh technology social enterprise startup. She continues to serve as a thought leader on issues of early-stage finance and clean energy commercialization for the World Bank's Climate Technology Program. She received her Master's in Public Policy from the Harvard Kennedy School and her Bachelors of Science in Electrical Engineering and Computer Science from MIT.

Eric Hsieh is the Director for Energy Finance and Incentives Analysis in the Energy Policy and Systems Analysis Office at the U.S. Department of Energy. His team analyzes how federal policies influence energy and financial markets. He was previously the Director of Business Development at Nexans, Director of Market Development at A123 Systems, the Government Relations Manager at the National Electrical Manufacturers Association, and on staff at the Federal Energy Regulatory Commission (FERC). Eric holds a Master in Public Policy from UC Berkeley and a B.S. in Computer Science and Engineering from MIT.

Dr. Mallikarjun (Arjun) Shankar's research focuses on the interdisciplinary bridge between computer science and the basic and applied sciences. He is the Director of ORNL's Compute and Data Environment for Science (CADES) institute which hosts joint scientific initiatives between the computing directorate and ORNL's science focus areas including environmental and biological sciences, materials and neutron science, nuclear science, and the physical sciences. Dr. Shankar received his Ph.D. in Computer Science from the University of Illinois, UrbanaChampaign, and then worked in industry designing and building next-generation data management infrastructures. His research in the national laboratory setting has involved designing national-scale sensor networking systems, energy infrastructure monitoring and control frameworks, and mechanisms to perform integrated data analytics and modeling and simulation. He is a member of the ACM and the IEEE Computer Society.

\section{Introduction}

The finance team in the Office of Energy Policy and Systems Analysis (EPSA-50) provides datadriven policy analysis to inform energy policy deliberations. To that end, EPSA develops and maintains analytical tools and capabilities for understanding the role of finance and financial policy in the energy sector. 
In the context of federal policy deliberations, quantitative analysis requires data at the company and asset level, collected nationally. Financial data that is both granular and uniform rarely exists in the highly fragmented power sector industry. Multiple entities collect power sector financial data, ranging from the Federal Energy Regulatory Commission (FERC), to regional transmission organizations (RTOs) and independent system operators (ISOs), to state regulatory bodies. Each of these actors plays a different role in the overall U.S. power system, which can complicate the exchange of relevant information.

The project team, led by EPSA, collected revenue information from relevant sources to piece together revenue flows within the U.S. electricity system to understand the complex relationships among specific actors within the market. Data scientists at Oak Ridge National Lab used this data to map these revenue flows into Sankey visualizations.

\section{Theory}

Sankeys are flow diagrams that depict a set of dynamic relationships in a system. The Irish captain Matthew Henry Phineas Riall Sankey first used this diagram in 1898 to depict the energy efficiency of a steam engine [1]. Research organizations commonly use Sankeys to describe physical resource flows. For example, domestically, the Lawrence Livermore National Laboratory maintains energy, carbon, and water flow charts at the international, state, municipal, and organizational level [2]. Internationally, Eurostat, the statistical office of the European Union [3], and the International Energy Agency [4] maintain Sankeys depicting European and global energy consumption, respectively. This project extends the Sankey concept to describe the financial transactions that occur in exchange for physical flows of electricity through a Sankey diagram as a use case for the Energy Finance Data Warehouse.

\section{Methodology}

\subsection{Energy Finance Data Warehouse}

EPSA-50 commissioned the Energy Finance Data Warehouse (EFDW) project to aggregate financial information from a variety of data sources. EFDW is composed of three parts: the EFDW repository, EFDW data view interpreter ${ }^{\mathrm{i}}$, and EFDW visualization dashboards. The 
EFDW is currently stored in an Excel database, but may change platforms; the purpose of the EFDW is to be the foundation for data collection in the industry for future analysts and the public.

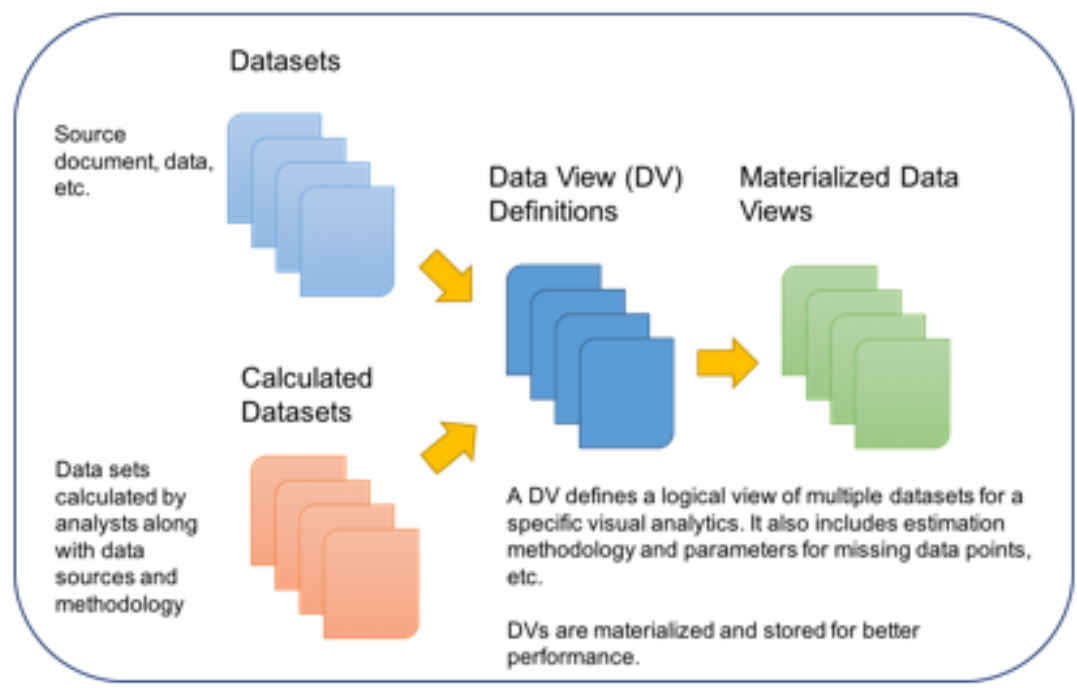

Figure 1: Data stored in the EFDW repository

Information stored in the EFDW repository includes data, metrics, and projections associated with company financials and physical assets. The data stored in EFDW can be grouped into the following categories: generic datasets, calculated datasets, data views ${ }^{\mathrm{ii}}$, and materialized data views. The datasets are organized and indexed so that EPSA analyst can quickly identify what datasets are available for analyses.

\begin{tabular}{|l|l|l|}
\hline Data Type & Required Modifications & Source (Example) \\
\hline Generic datasets & None & EIA, RTO/ISOs (PJM, CAISO) \\
\hline Calculated datasets & $\begin{array}{l}\text { Manual calculations by EPSA } \\
\text { Analyst }\end{array}$ & $\begin{array}{l}\text { EPSA calculations joining EIA and } \\
\text { EEI }\end{array}$ \\
\hline Data views & ORNL Java programming & n/a \\
\hline Materialized data views & $\begin{array}{l}\text { ORNL EFDW Data View } \\
\text { Interpreter module }\end{array}$ & n/a \\
\hline
\end{tabular}

Table 1: Datasets stored in EFDW Repository

The first use case chosen for the EFDW was the Sankey; the team is currently exploring other visualization use cases.

\subsection{EFDW visualization dashboard}

The analyst team determined that no single existing software tool could provide all desired analytical and visualization capabilities. Consequently, the team developed a set of front-end 
graphical user interfaces known as EFDW visualization dashboards. These dashboards let analysts view illustrations of the data from the EFDW repository. As a specific use case for the EFDW, Sankey diagram dashboards allow analysts to interact with diagrams displaying the context around the data points in which they are interested. The EFDW visualization dashboards incorporates existing web tools, including Infocaptor (which provides access to Tableau), SankeyMATIC, and Sankey Diagram Generator visualizations.

\begin{tabular}{|l|l|l|}
\hline Software Type & Advantage & Disadvantage \\
\hline Infocaptor Enterprise & $\begin{array}{l}\text { Allows users to compose customized } \\
\text { dashboards with various interactive } \\
\text { visualizations, including Sankey } \\
\text { diagram. }\end{array}$ & $\begin{array}{l}\text { Lacks features such as assigning levels } \\
\text { to nodes, so users need to manually } \\
\text { position nodes. Nodes and the edge flow } \\
\text { colors cannot be configured or selected } \\
\text { based on a criteria/attribute. }\end{array}$ \\
\hline Tableau & Intuitive drag and drop interface. & $\begin{array}{l}\text { Does not natively support Sankey } \\
\text { generation. }\end{array}$ \\
\hline SankeyMATIC & $\begin{array}{l}\text { Gives option to users to assign colors } \\
\text { to nodes and flows. }\end{array}$ & $\begin{array}{l}\text { Does not support assigning layers to } \\
\text { nodes, so users need to manually adjust } \\
\text { position of nodes. }\end{array}$ \\
\hline Sankey Diagram Generator & $\begin{array}{l}\text { Supports various features such as self- } \\
\text { loops, moving around nodes, and } \\
\text { changing opacity and the density of } \\
\text { flows, which are necessary for creating } \\
\text { sophisticated Sankey diagrams. Tool } \\
\text { also supports explicitly assigning layer } \\
\text { numbers to nodes in the diagram. }\end{array}$ & $\begin{array}{l}\text { Tool does not allow users to assign } \\
\text { colors to nodes and flows. A user needs } \\
\text { to convert his/her own dataset into a } \\
\text { JSON document following a specific } \\
\text { structure to import dataset into the tool. }\end{array}$ \\
\hline
\end{tabular}

Table 2: Overview of Software Tools used to create Visualization Dashboards

EFDW Visualization Dashboards

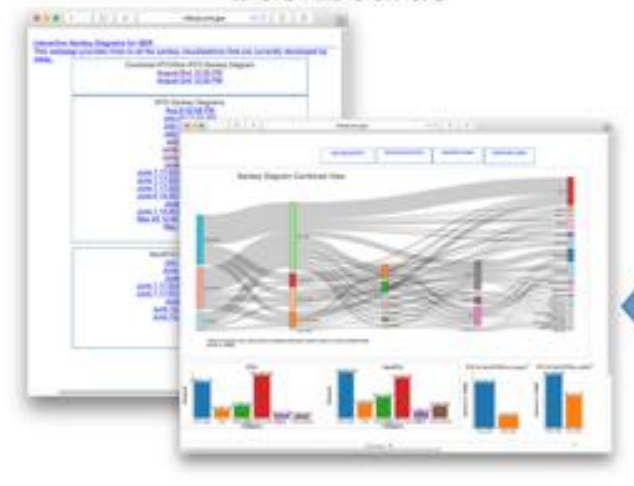

EFDW Repository

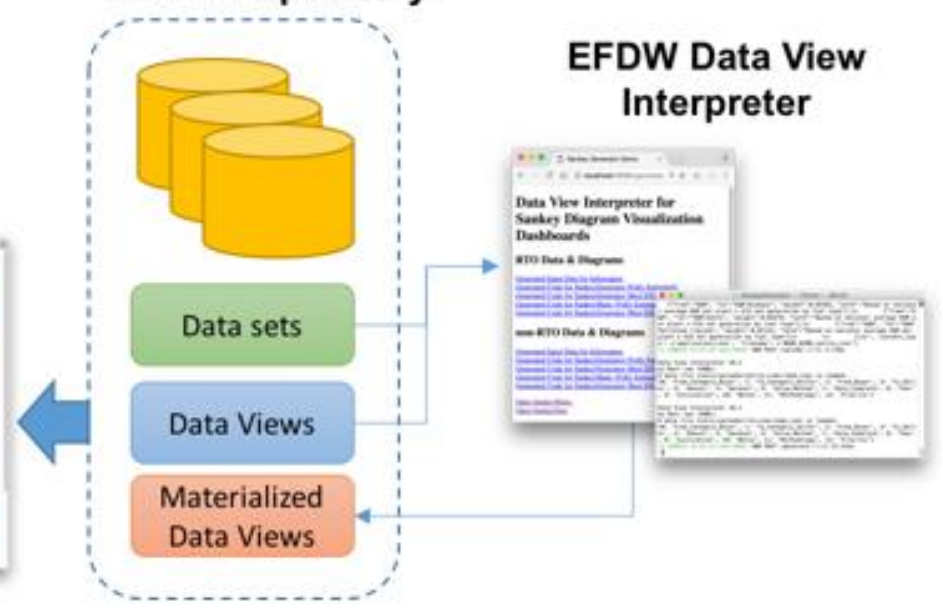

Figure 2: Overview of Energy Finance Data Warehouse components 


\section{Discussion}

The Sankey visualization assumes that every unit of delivered electrical energy corresponds to a payment for power, where the payment flows run opposite to electricity flows. The visualization depicts the net value of transactions between two entities and excludes trades or hedges not tied to physical delivery of electricity. ${ }^{\text {iii }}$ The visualization also excludes electricity consumption from distributed energy resources.

The Sankey follows the movement of revenues from the initial customer, the end user, through the distributor, transmitter, generator, and fuel and operations and maintenance (O\&M) companies. The Sankey given as an example (Figure 3) uses data from 2014, when end users spent approximately $\$ 390$ billion on electricity.

The Sankey simplifies relationships to graphically represent the flow of funds. For instance, electricity is bought and sold in either vertically integrated or centrally organized markets. The calculations for revenues are slightly different for the two categories, but revenues are combined in the final Sankey; end users may pay retail marketers directly or through the incumbent utility, depending on state regulations. In addition, functions such as generation, transmission, and distribution are depicted separately even if an IOU is vertically integrated. 


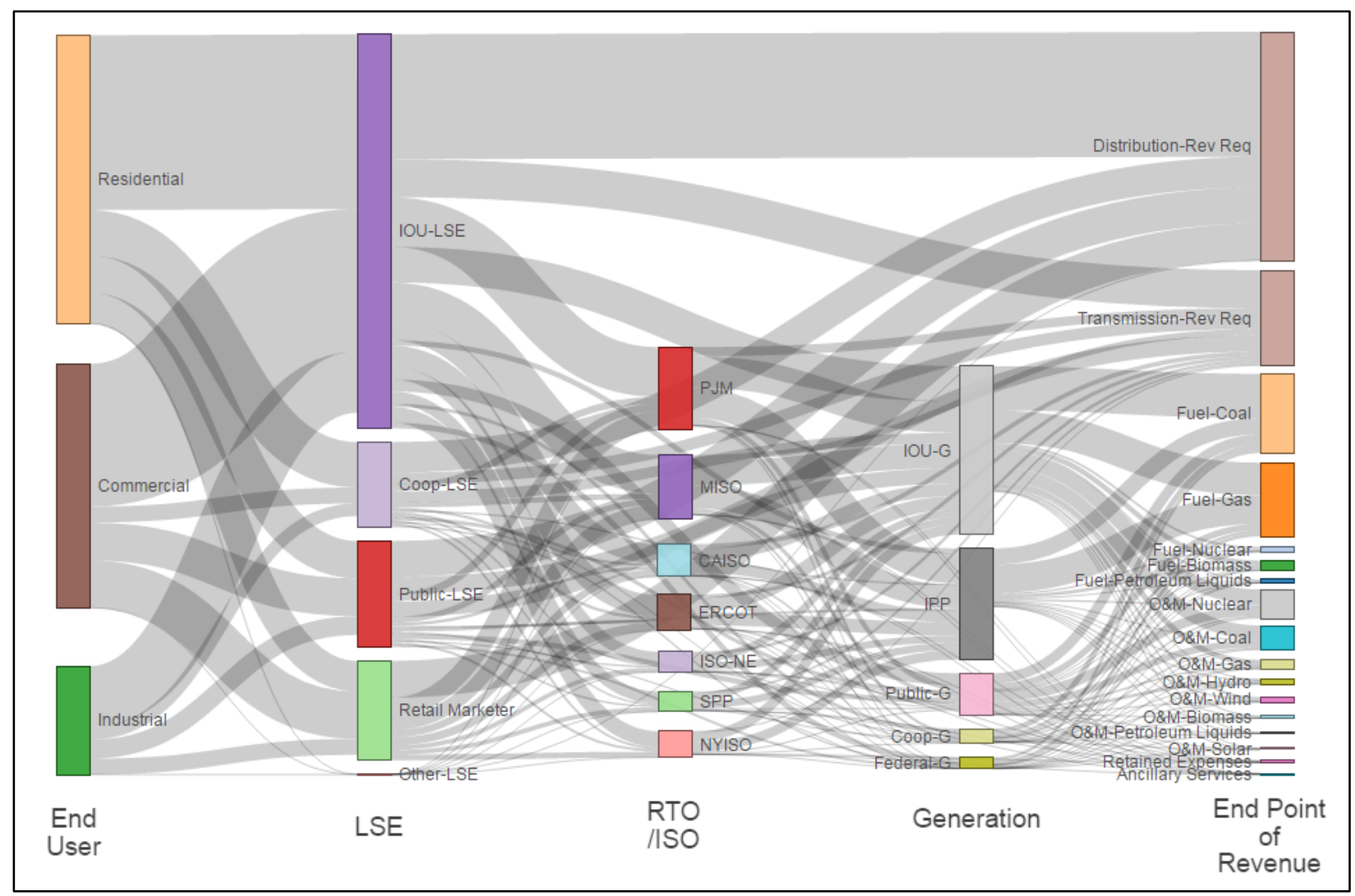

Figure 3: Simplified revenue flows through the U.S. power sector value chain, 2014

Revenue payments start in Figure 3 from the leftmost column depicting end users. Residential, commercial, and industrial consumers account for about 40\%, 40\%, and 20\%, respectively. End users pay the load-serving entity (LSE), which owns and operates the distribution system, shown in column 2. LSEs include large investor-owned utilities (IOUs) as well as public power (municipal, state-owned, federally owned, and political subdivision power), cooperatives, and retail marketers (which do not own generation and use the transmission and distribution of other utilities). IOUs, cooperatives, and public power compose about $60 \%, 10 \%$, and $15 \%$ of revenues, respectively. Retail marketers are almost $20 \%$ of revenues, but primarily operate in centrally organized markets.

LSEs then procure power. About two-thirds and one-third of power is sold in centrally organized and vertically integrated markets, respectively.

In vertically integrated regions, the LSE, such as Duke Carolinas or Alabama Power, owns generation and transmission and may buy power on the margin from other vertically integrated 
utilities through power pools. Vertically integrated LSEs allocate 30\%, 20\%, and 50\% of revenue for distribution (the distribution revenue requirement), transmission, and generation, respectively. (These proportions are elaborated on in Table 3.) Generation revenues are then allocated to fuel and O\&M expenses.

On the other hand, in centrally organized markets, load-serving entities (LSEs), such as Pepco and Pacific Gas \& Electric, generally procure power from generators, pay for transmission rights, and spend to operate and expand the LSE's distribution functions. In RTO/ISO regions, all electricity flows go through the RTO/ISO, so all procurement of power by the LSE shows up as a transaction through the respective RTO/ISO. The RTO/ISO then passes payment onto transmission and generation. The largest RTO/ISOs are PJM and MISO, accounting for about $30 \%$ and $20 \%$ of revenues, respectively.

In RTO/ISO regions, power is procured through the RTO/ISO exchanges (day-ahead or real-time markets), bilateral contracts with non-utility generators, independent power producers (IPPs), and some degree of self-supply (LSE-owned), depending on state regulations. The Sankey diagram assumes that all transactions are cleared through the market operator. The flows do not distinguish power bought on the exchange, through bilateral contracts, or self-supplied. Flows through an RTO/ISO thus are payments made from an LSE in the RTO/ISO footprint. This simplification was made due to a lack of data availability and constraints of the visualization medium.

The Sankey diagram also simplifies payments to generators by using fixed proportions, where possible; the rationale for each is elaborated on in Table 3. Generator compensation is actually determined through a mix of energy payments, capacity payments, out-of-market transactions, penalties for not meeting dispatch commands, and so on. Bilateral contracts are also transacted through the RTO/ISO and corrected for with outside payments between the generator and LSE (contracts for differences), which are not tracked by the RTO/ISO. 
Finally, about $60 \%$ and $30 \%$ of generation expenditures go to fuel and O\&M, respectively. Approximately $55 \%$ of fuel costs are for natural gas and about $50 \%$ of O\&M costs are for nuclear plants.

The team characterized data quality within the EFDW as exact, calculated, and estimated. Where available, direct company- or transaction-level data have been aggregated to create very highquality overview numbers. In some cases, a calculation using two or more data sources can produce a derived financial flow. Some financial flows required simplifying assumptions. Table 3 summarizes these assumptions.

\begin{tabular}{|c|c|c|}
\hline Data Element & Simplification & Rationale \\
\hline $\begin{array}{l}\text { From LSEs to Distribution, Central } \\
\text { Organized }\end{array}$ & $33 \%$ & $\begin{array}{l}\text { Based on observed ratios, and load } \\
\text { ratio of each ownership type as } \\
\text { calculated from EIA861 }\end{array}$ \\
\hline $\begin{array}{l}\text { From LSEs to Generation, } \\
\text { Vertically Integrated }\end{array}$ & $50 \%$ & Based on informed estimation \\
\hline $\begin{array}{l}\text { From LSEs to Transmission, } \\
\text { Vertically Integrated }\end{array}$ & $20 \%$ & Based on informed estimation \\
\hline $\begin{array}{l}\text { From LSEs to Distribution, } \\
\text { Vertically Integrated }\end{array}$ & $30 \%$ & Based on informed estimation \\
\hline From LSEs to Each RTO & & $\begin{array}{l}\text { Based on ratios of each RTO/ISO's } \\
\text { revenue divided by total revenues }\end{array}$ \\
\hline From RTOs to Generation & $77 \%$ & Based on PJM's ratio \\
\hline $\begin{array}{l}\text { From LSEs/RTOs to Each } \\
\text { Generation }\end{array}$ & (within 50\%/77\%) & $\begin{array}{l}\text { Based on sum of EIA923 } \\
\text { generation by ownership type } \\
\text { divided by sum of all EIA923 } \\
\text { generation }\end{array}$ \\
\hline From RTOs to Transmission & $33 \%$ & Based on PJM's ratio \\
\hline From RTOs to Each Transmission & (within 33\%) & $\begin{array}{l}\text { Proportion of transmission revenue } \\
\text { requirements by ownership reported } \\
\text { by CAISO in } 2014\end{array}$ \\
\hline $\begin{array}{l}\text { From Generation to Each Fuel and } \\
\text { O\&M }\end{array}$ & & $\begin{array}{l}\text { Based on EEI's national averages } \\
\text { of fuel/O\&M cost multiplied by } \\
\text { total generation by fuel type from } \\
\text { EIA923 }\end{array}$ \\
\hline
\end{tabular}

Table 3: Assumptions used in EFDW and Sankey Visualization

\section{Lessons learned}

\subsection{Limitations of revenue metric}

The use of revenues as the basis of financial transactions means the Sankey does not indicate profitability. Although each entity has outflows to other parts of the power sector value chain, other expenditures are not accounted for, including capital expenditures, taxes, dividend 
payments, debt service payments, overhead, and retained earnings. The Sankey also does not incorporate a business' financial activities such as debt and equity flows.

\subsection{Data availability}

Many transactions on the Sankey are not included in utilities' required reporting data. The team tried multiple sources of data, including public information from federal energy regulators and agencies (EIA, FERC), public information from regional and state sources (the RTO/ISOs, the public utility commissions (PUCs)), public information from other agencies (10-K filings from the SEC), and proprietary data (SNL, BNEF, IHS). The team nevertheless ran into multiple major data gaps.

FERC only has data for FERC-jurisdictional entities, and key forms providing revenue data (FERC Form 1, FERC EQR, EIA Form 861, and EIA Form 923) are only required for utilities that meet a certain threshold of load served. SEC 10-K filings are limited only to publicly traded IOUs. Much other data is aggregated at the state level, the quality and public availability of which is very spotty. Utilities may report data needed for the Sankey (such as the revenue requirements for generation, transmission and distribution in vertically integrated regions) in rate cases with PUCs, but the public availability of that data is state by state. In general, data is less transparent in vertically integrated regions than in centrally organized markets.

Data on payments to generators from RTO/ISOs is available, but is not publicly distributed by the RTO/ISOs. Furthermore, this data would be difficult to use because one kWh of electricity can be traded multiple times, increasing the difficulty of tracking the underlying physical transaction.

Public power and cooperatives report some data to USDA, but the quality and completeness of this data is unclear. Finally, non-power entities are not required to report data. Corporate procurements generally are confidential, and existing corporate procurement power purchase agreement (PPA) databases are often incomplete or inaccurate. 


\subsection{Constraints of off-the-shelf software}

Although the use of Sankey to display financial flows is a simple one, implementation was constrained by the limitations of various software packages. One of the challenges of the project was the balance of detail for accuracy with simplicity to visualize overall trends. The policy question is an input to the level of detail required. The Sankey implementation ideally would allow the user to increase or decrease the level of resolution depending on the scale and scope of the question.

\section{Use case examples}

A simplified flow of funds diagram can help guide U.S. federal policy priorities. The U.S. federal government has a range of policy tools that could be used to catalyze private sector activity. For example, Congress has passed and renewed federal tax credits intended to spur the deployment of renewable generation technologies. The Sankey can help policymakers better understand how specific federal incentives might alter capital flows to different stakeholders throughout the system.

In addition, the Sankey has the potential to illuminate policy discussions, as in the examples below.

\subsection{Capex of generation versus fuel cost}

The Sankey diagram was simplified to describe the flow of funds directly from ratepayers to generation types through the system, but the Sankey diagram could also be used to describe the tradeoff between the upfront costs of capital expenditures on various generation types vs. the cost of fuel. Renewable generation technologies are characterized by high upfront capital costs and no long-term fuel cost. In contrast, natural gas power generation may have a relatively smaller upfront capital cost but significant long-term fuel costs. The Sankey structure could explore this dynamic by conducting sensitivity analysis around the upfront and O\&M costs for various power generation technologies. Detailed information about the ownership patterns for different technologies would help inform which entities would be more or less impacted by particular cost reductions. The Sankey could focus attention on particular market types or regions that would be more or less affected by particular changes in O\&M costs. 


\subsection{Changes in the price of natural gas}

Natural gas prices have exhibited significant volatility, from a peak Henry Hub spot price of $\$ 8.86 /$ MMBtu in 2008 to $\$ 2.75 /$ MMBtu in 2012 [5]. Price increases are passed through the electricity system to ratepayers. The financial Sankey could help analysts and policymakers explore how these costs would affect asset owners and commercial, industrial, and residential electricity consumers. This analysis would require more detailed assessment of the cost of fuel inputs to the Sankey and the impact from higher natural gas prices. For instance, the ability to switch from natural gas to coal might mitigate and complicate the impact of an increase in natural gas prices on the electricity system.

\section{Conclusion}

The EFDW systematically organizes complex datasets in a manner that enables analysts to quickly explore a range of energy policy issues. One implementation of the EFDW was the development of the Sankey diagram that illustrates the complex set of revenue flows across the power sector.

The Sankey should be understood as a new tool to facilitate discussion, interpretation, analysis, and exploration of financial transactions across the electricity system, not as a definitive answer on any specific item. The team strived to create the most accurate depiction of revenue flows possible. However, the challenge of presenting a usable framework that depicts a complex set of financial transactions and relying on numerous data sources and methodologies, welcomes more work iterating on this approach. Developers should continue to consider the questions the Sankey might answer and the level of detail required to answer each question. Given the number of relationships included in the Sankey, it is important for analysts to prioritize their investigation to the most relevant financial relationships for the questions they are asking.

Although there were difficulties in data acquisition and translation over multiple software platforms to create the final Sankey visualizations, the primary benefit of this graphic to a federal policymaker is the ability to see and understand the big picture of power sector revenue flows. For example, federal tax credits have been used as upstream policy interventions to target power 
plant project economics and the Sankey can help elucidate the effect on downstream end users. The Sankey also helps users visualize sizing of power sector revenues. For example, revenues from residential consumers are slightly higher than that from commercial, and IOU-owned LSEs receive about half of end user payments in the U.S. Furthermore, the use case examples presented, capex vs. O\&M costs and the impact of natural gas price fluctuation, indicate further opportunities to use the current Sankey visualization to understand the implications of policy interventions. 


\section{REFERENCES}

[1] EIA, "Electric power sales, revenue, and energy efficiency Form EIA-861 detailed data files," 2 August 2016. [Online]. Available: https://www.eia.gov/electricity/data/eia861/.

[2] EIA, "Form EIA-923 detailed data,"July 27, 2016. [Online]. Available: https://www.eia.gov/electricity/data/eia923/.

[3] EIA, "Form EIA-860 detailed data," June 17, 2016. [Online]. Available: https://www.eia.gov/electricity/data/eia860/.

[4] FERC, "Form 1 - Electric Utility Annual Report," Dec. 22, 2015. [Online]. Available: http://www.ferc.gov/docs-filing/forms/form-1/data.asp.

[5] EEI, "Statistical Yearbook of the Electric Power Industry," EEI, Washington, 2016.

[6] P. Paul Sotkiewicz, "Markets Report," Jan. 20, 2015. [Online]. Available: https://www.pjm.com/ /media/committees-groups/committees/mc/20150120-webinar/20150120item-09a-markets-report.ashx.

[7] SNL, "An Overview of Transmission Ratemaking in the California ISO," SNL, Edison, 2016.

\footnotetext{
${ }^{\mathrm{i}}$ EFDW Data View Interpreter is a software module that is responsible for parsing data views and materializing them in physical datasets so that data views can be exploited for various analyses. The materialized datasets are also stored in the EFDW repository. For a proof-of-concept, the team developed EFDW Data View Interpreter for EFDW's Sankey diagram visualization dashboards.

${ }^{\text {ii }}$ A data view is a definition of a virtual dataset constructed from other datasets in the repository. Analysts can describe their needs in their data view definitions. For instance, a data view can describe an input dataset for EFDW's Sankey diagram visualization dashboards, where the data view includes the related available data, structure of Sankey diagram, and proportions for computing unavailable data points. Data views themselves cannot be utilized directly for analyses. Data views describe how to construct datasets as structured JSON documents.

iii The exception is RTO/ISO retained expenses, which are accounted for as a small outflow from the RTO/ISOs.
} 